Archivum, LXIX, 2019, pp. 251-275

\title{
Memorias de un tiempo posible. Historias alternativas en la novela mexicana contemporánea
}

\author{
Francisco Javier Ordiz Vázquez \\ UNIVERSIDAD DE LEÓN \\ fjordv@unileon.es
}

Recibido: 10/09/2019

Aceptado: 16/12/ 2019

\section{RESUMEN:}

El objetivo de este trabajo consiste en analizar el tópico de la historia alternativa y sus distintas formas de expresión en la narrativa mexicana reciente. En Si tú quieres, moriré, Gerardo Laveaga se inscribe en la tradición de los estudios de la llamada "filosofía de lo mexicano" a la hora de proponer a través de un desarrollo histórico ficticio una reflexión sobre ciertos momentos clave en los que México perdió la oportunidad de cambiar su futuro. Otro tipo de historias alternativas, como las que ofrecen Tiempo lunar de Mauricio Molina y las dos novelas de Gabriel Trujillo Muñoz que aquí se analizan, se alejan del modelo ucrónico de carácter contrafactual que representa el relato de Laveaga, y desarrollan sus argumentos a partir del tópico del viaje temporal o interdimensional con un fundamento teórico basado en hipótesis científicas. En todos los casos, esta propuesta de mundos alternativos implica una valoración negativa del presente y de una Historia que tanto en clave nacional como en un aspecto más universal o genérico se interpreta como un proceso marcado por la intolerancia, la violencia y el rechazo al diferente.

PALABRAS CLAVE: Ciencia-ficción, ucronía, novela, México. 
Memories of a possible time frame. Alternative histories in contemporary Mexican novels.

\begin{abstract}
:
The objective of this article is to analyze the topic of alternative history and its various manifestations in recent Mexican narratives. In his novel Si tú quieres, moriré [If you want me to, I will die], Gerardo Laveaga joins the study of the so-called "philosophy of the Mexican" and presents, though a historical and fictional plot, a reflection on the key moments in which Mexico lost the chance to change its future. Other type of alternative histories, such as the ones imagined by Mauricio Molina in Tiempo lunar [Moon time] and the two novels by Gabriel Trujillo Muñoz analyzed in this article, step away from the counterfactual and uchronic model represented by Laveaga's work and imagine a type of interdimensional journey or time travel which can be explained scientifically. In all cases, this imagination of alternative worlds implies a negative assessment of the present and of a History which, both nationally and internationally, is marked by intolerance, violence and the rejection of difference.
\end{abstract}

KEYWORDS: Science-fiction, uchronia, novel, Mexico

El interés por el estudio de la ciencia ficción en el contexto general de la literatura latinoamericana se ha visto incrementado en los últimos años y ya empieza a contar con una cierta presencia en medios y eventos académicos oficiales en los que hasta hace pocas fechas no habría tenido cabida. A la creciente bibliografía, entre la que caben destacar los estudios de Claudio Capanna (1966), Yolanda Molina-Gavilán (2002), Luis C.Cano (2006), Fernando Reati (2006), Miguel López-Lozano (2008), Rachel Haywood Ferreira (2011), Rudyard Alcocer (2011), Antonio Córdoba Cornejo (2011) , Ginway y Brown (2012), o Gabriel Trujillo Muñoz (1999, 2000, 2016), se suma la celebración de congresos y simposios dedicados al tema (Madrid 2008, Lima 2011-2103, Berlín 2013) o la publicación de monográficos de revistas prestigiosas como es el caso del volumen de la Revista Iberoamericana del año 2012 titulado "La ciencia ficción en América Latina: entre la mitología experimental y lo que vendrá" (no 238-239). 
Junto a estos estudios particulares centrados en América Latina, existe también un importante caudal de bibliografía crítica destinado a elucidar cuestiones puramente teóricas y definir las características, alcances y límites del género. Obras como las de Darko Suvin (1984), Carl Freedman (2000), James Gunn y Matthew Candelaria (2005) o Fredric Jameson (2009), se han convertido ya en fuentes relevantes para abordar un estudio de estas características. Autores como Fernando Ángel Moreno (2010) o David Seed (2011) han ofrecido asimismo una valiosa clasificación de las diferentes modalidades o subgéneros de esta vertiente narrativa. Moreno en concreto se basa en la distinción que habitualmente se establece en toda taxonomía del género entre la "hard science-fiction" y la "soft sf" (Seed, 2011,50), para diferenciar la "ciencia-ficción tradicional" representada principalmente por las aventuras espaciales o space opera, de lo que denomina "literatura prospectiva" (2010,116-118), que articula sus argumentos en la proyección hacia el porvenir ya no de planteamientos basados en los avances científicos y tecnológicos, sino en las llamadas "ciencias humanas", como la psicología, la antropología, la sociología o la historia. Estaríamos en este caso ante la creación de utopías y especialmente distopías, que cuentan con una notable presencia en la literatura del siglo XX. Estos relatos nos sitúan en un futuro imaginario en el que, por lo general, se proyectan todos los miedos y amenazas del tiempo de creación. Frente a estos argumentos tradicionales de la ciencia ficción, las ucronías o historias alternativas -en este trabajo usaré ambos términos como sinónimos- representan un tipo especial de ficciones prospectivas que no dirigen su mirada hacia el porvenir sino hacia un pasado o presente imaginarios. Como primer paso para analizar su presencia en la novela mexicana de las últimas décadas, objeto principal del presente trabajo, conviene por tanto definir las características e implicaciones teóricas que presenta esta modalidad narrativa.

\section{La ucronía o historia alternativa.}

Investigadores como David Seed, Fernando Ángel Moreno o Karen Hellekson (2001) han coincidido a la hora de considerar a 
las ucronías como una de las expresiones o subgéneros de la ciencia ficción que, por tanto, participa en primera instancia de aspectos relevantes del género como la relación entre "el tiempo de la narración y la realidad referencial" (Cano, 2006,60) o el efecto de "extrañamiento", que Jameson define como "una renovación conmocionada de nuestra visión que de nuevo, y como si fuera por primera vez, nos permite percibir su historicidad y su arbitrariedad, su profunda dependencia de los accidentes de la aventura histórica del hombre" $(2009,304)$. En un aspecto más concreto, analistas como Cristina María Pons $(1996,62)$ o Humberto Beck (2008) han relacionado esta modalidad narrativa con la novela histórica. En esta línea, Moreno señala que la ucronía coincide con las utopías y distopías en la ficcionalización verosímil de un mundo posible, pero frente a ellas posee un mayor anclaje en la realidad histórica, lo cual no permite a sus autores tanta libertad en la creación de unos escenarios que deben mantener un apego esencial con los episodios o momentos reales de los que parten $(2010,258)$. Esa imaginación del porvenir, que en las expresiones más frecuentes de lo prospectivo se sitúa en un tiempo futuro en relación al momento de la escritura, se hace partir en este caso de lo que Seed describe como "a point of divergence, a fork in the past of history which goes in a different direction" (2011,111). Ese "punto de divergencia" o "nexus event", como lo denomina Karen Hellekson $(2001,5)$, es conocido también como "punto Jonbar", en referencia al personaje de un relato de Jack Williamson a quien se le planteaban dos posibilidades de elección que determinarían futuros distintos. La realidad paralela o alternativa puede tener por tanto una dimensión individual, cuando el dilema se centra en las alternativas vitales de un personaje concreto, o colectiva cuando en este proceso se involucra toda una comunidad. En este último caso, el desarrollo de los acontecimientos a partir de este instante crucial puede dar lugar a nuevas formas de utopías o distopías en función del tipo de mundo imaginado, que en general tienen relación con el grado de aceptación o conformismo que el autor en cuestión o la tradición a la que pertenece tienen con su Historia. 
Un repaso a algunas de las ucronías más destacadas en la literatura occidental pone en evidencia la existencia de relatos que muestran un escenario de pesadilla nacido a partir de acontecimientos alternativos como la victoria de la Armada Invencible en novelas como Pavana (1968), de Keith Roberts, o Britania conquistada (2002), de Harry Turtledove. Si en esta última los acontecimientos apenas exceden del periodo histórico tratado, Roberts dibuja el panorama de una Inglaterra actual convertida en un país atrasado dominado por el fanatismo católico. Más frecuente resulta el recurso de especular sobre la derrota de los aliados en la Segunda Guerra Mundial, como sucede en El hombre en el castillo (1962) de Philip K. Dick, Hitler victorioso (1990), de Gregory Benford o La conjura contra América (2011), de Philip Roth. La lectura de estos relatos deja en el lector un poso final de alivio cuando compara su realidad con lo que pudo haber sucedido de haber sido otras las circunstancias, de forma que estas historias se enfocan más bien a presentar los "aciertos" del pasado, que han librado al país y al mundo de un destino sombrío. Frente a esta tendencia tan extendida en la literatura anglosajona de las últimas décadas, las escasas expresiones ucrónicas en México han tendido por lo general a plantear, valga la paradoja, una utopía negativa, es decir a describir a partir de ese punto de convergencia un mundo mejor del que existe en el presente, que se ha podido construir mediante la eliminación de algunos de los dramáticos episodios que han jalonado la historia del país, y que a la postre deja en el lector un regusto amargo al enfrentarlo con su auténtica realidad. El sesgo de este tipo de ucronías va en consonancia con el tono habitual de la novela histórica, que con frecuencia supone una revisión de los fracasos y utopías incumplidas que han caracterizado la trayectoria de México desde su nacimiento. Las historias ucrónicas se plantean por tanto como una suerte de reflexión acerca de los errores cometidos y una recreación idílica de un mundo que pudo haber sido posible.

Desde el punto de vista filosófico, la ucronía pone el foco en cuestiones como la libertad de elección y la importancia tanto de 
las propias decisiones como del azar como factores que marcan el destino individual y colectivo. Este tipo de contenidos, que constituyen el elemento nuclear de esta expresión artística, se encuentran también en la línea medular de las especulaciones sobre la historia y la identidad de México recogidas en el corpus teórico del debate sobre la llamada "filosofía de lo mexicano", que con una orientación que conjugaba el psicoanálisis con el existencialismo pretendió poner al descubierto los "traumas" que determinaron el carácter y el destino del país. En el aspecto narrativo, el potencial de la ucronía queda claramente perfilado en novelas como La muerte de Artemio Cruz (1962) de Carlos Fuentes, que bajo la influencia de las teorías que había expresado Octavio Paz en su fundamental estudio El laberinto de la soledad (1959), planteaba el destino del personaje como un camino forjado a través tanto de sus elecciones personales como de los avatares fortuitos de su existencia. Las alternativas vitales de Cruz se exponen en los segmentos en segunda persona especialmente a través del tema del doble. Ya desde su propio nacimiento es Artemio el que sobrevive mientras que parece que su hermano gemelo muere a manos de su padre (1962,315). Más tarde, también conservará la vida durante la revolución, en tanto que otros compañeros de armas, como el anónimo soldado que, como dice la voz narrativa, "si tuviese los ojos verdes, sería su gemelo..." (1962,75), es abatido en la contienda. Finalmente, Artemio se apropiará del destino de Gonzalo Bernal, a quien conoce en la cárcel de Perales donde será fusilado. La trayectoria vital de Artemio se define por unas circunstancias en las que se conjuga la libertad de elección y el azar y en todos sus momentos relevantes flotará a su lado la posibilidad de haber corrido otra suerte, de haber vivido otra vida: "elegirás, para sobrevivir elegirás, elegirás entre los espejos infinitos uno solo (...) decidirás, escogerás uno de los caminos, sacrificarás los demás: te sacrificarás al escoger, dejarás de ser todos los otros hombres que pudiste haber sido" $(1962,209)$. En la medida en la que el destino del personaje se identifica en la novela con el del propio país, la historia de Artemio Cruz supone 
en el fondo una reflexión poco complaciente sobre la historia de México. La voz narrativa en segunda persona analiza las raíces profundas de esta suerte de sino fatal que ha implicado la derrota cíclica de todo proyecto utópico o regenerador, esa dialéctica o maldición de "la chingada" que ha significado violencia y desunión, y que tanto Paz como Fuentes consideran la causante de los males que han marcado el devenir histórico de la nación ${ }^{1}$. El sesgo determinista que parece derivarse de esta interpretación de la Historia se pone no obstante en cuestión cuando se vislumbra la posibilidad de un cambio mediante la fuerza y el poder de la colectividad. Frente al derrotismo, se atisba un posible futuro de esperanza si el mexicano toma consciencia de su realidad y su historia y reacciona contra la "chingada" y lo que significa: "déjala en el camino, asesínala con armas que no sean las suyas: matémosla: matemos esa palabra que nos separa, nos petrifica, nos pudre con su doble veneno de ídolo y cruz: que no sea nuestra respuesta ni nuestra fatalidad" $(1962,146)$.

\section{La historia contrafactual: Si tú quieres, moriré.}

El tema de la historia alternativa, tan solo sugerido en $L a$ muerte de Artemio Cruz, se encuentra desarrollado de forma explícita en la reciente novela de Fernando Laveaga Si tú quieres, moriré (2018).

$\mathrm{Al}$ igual que Fuentes, Laveaga realiza una incursión hacia el pasado en busca de las claves que han hecho de México lo que es en la actualidad. Si en el caso anterior el análisis se centraba en el periodo revolucionario, en esta novela el foco de atención se fija en un momento no muy estudiado en la historia del país: los años que siguieron a la independencia y especialmente la época del gobierno del general Santa Anna.

En el aspecto narratológico, Si tú quieres, moriré presenta una estructura de carácter fragmentario en la que participan diferentes voces narrativas. El peso principal del relato recae en los

1 Sobre la interpretación simbólica de "la chingada" y sus implicaciones históricas, ver el capítulo IV de El laberinto de la soledad (Paz,1993,202-227) 
segmentos en los que María Inés Vázquez de Zermeño, el único personaje ficticio de la obra, se dirige en segunda persona a su interlocutor ausente, antiguo amante y figura central de la narración: Valentín Gómez Farías. Esta voz sigue paso a paso la actividad pública del personaje, que va reconstruyendo tanto a partir de la información que le proporcionan las cartas que él mismo le envía como de las que recibe de otro personaje relevante, Francisco García Salinas, de sus tíos, y distintas noticias de prensa. Estos fragmentos, junto con las misivas de García Salinas que se transcriben de forma directa, sirven para informar también al lector sobre el pensamiento político, los planes y las dudas de este relevante miembro del ala liberal. La tercera instancia narrativa se sitúa ya claramente en el terreno de la imaginación e introduce a la novela en los dominios de lo insólito: en 1855, es decir, tres años después de su fallecimiento real, Lucas Alamán cuenta su experiencia como representante del gobierno mexicano en el Reino Unido y hace recuento de los hechos más relevantes acaecidos en su país en las últimas décadas, al tiempo que desgrana también su ideario y su propia trayectoria política.

El mosaico narrativo se compone por tanto de distintas voces y tiempos, en un esquema que recuerda la estructura de Noticias del Imperio (1987) de Fernando del Paso. Esta forma de contar los hechos conecta a Laveaga con las recientes tendencias de novela histórica, que abandonan la linealidad y la perspectiva única y ceden la voz principal a sectores de la población habitualmente marginados o silenciados: los jóvenes, los indígenas o las mujeres $^{2}$. Como forma de contrarrestar el papel concedido casi en exclusiva al varón en la historia oficial del país, Laveaga otorga el mayor peso específico del relato a María Inés, que aparece además como muñidora en la sombra del destino tanto de Gómez Farías como de su aliado García Salinas. Como una Mdme. de Merteuil mexicana, la mujer es la que realmente mueve los hilos del relato y ejerce como consejera y guía en los momentos más

2 Sobre las nuevas voces narrativas en la novela histórica hispanoamericana, ver Menton (1993), Rivas (2004) y Díez Cobo (2009) 
relevantes de la vida de ambos personajes, que en todo momento siguen sus advertencias y orientaciones. Así reflexiona María Inés sobre su papel: "Si yo quería ser parte del mundo, figurar en debates y reformas, estaba condenada a hacerlo por medio de un hombre" $(2018,44)$.

La ordenación cronológica de los sucesos narrados sigue el procedimiento habitual de la historia contrafactual ${ }^{3}$. En primera instancia, las distintas fuentes van ofreciendo una información extensa y detallada de las circunstancias que rodean el nacimiento de la república mexicana desde las consecuencias de la restauración borbónica en España hasta el gobierno del general López de Santa Anna. En el entramado narrativo comparecen los protagonistas principales de la Historia, que exponen sus planes y sus ideas, al tiempo que se va trazando en torno a ellos una compleja trama de intereses y ambiciones que desembocan de forma invariable en acciones violentas. El autor retrata de forma prolija el ambiente convulso de esa época, caracterizado por la lucha entre dos facciones irreconciliables: conservadores y liberales, que defendían proyectos distintos para el país. Esta pugna entre dos modelos contrapuestos, común a prácticamente todos los países de América Latina en las décadas posteriores a la independencia, encontró una de sus principales expresiones en Argentina, donde el enfrentamiento entre federales y unitarios dio pie a la teorización del conflicto por parte de Domingo Faustino Sarmiento en términos de la dicotomía civilización/barbarie. Si en el primer caso sus partidarios miraban hacia Europa y los países desarrollados del mundo, la segunda opción representaba sobre todo el pasado colonial y la ignorancia del pueblo cegado por el clero. La lucha encarnizada entre

3 Como señala Karen Hellekson, el término "contrafactual" suele aplicarse más al estudio de la Historia, frente al de "historia alternativa" más habitual en el estudio literario $(2001,3)$. En la medida en que la novela de Laveaga supone un ejercicio de reconstrucción minuciosa del periodo histórico tratado y de su posible desarrollo hipotético, su planteamiento se acerca más a este tipo de análisis histórico que al de la creación narrativa. 
ambos proyectos desangró al país y a parte de América Latina durante decenios, y sus ecos literarios, tanto en lo relativo al ensayo como en el campo de la narrativa, se perciben en obras que tuvieron gran éxito y difusión en la literatura argentina como el mencionado texto de Sarmiento, El matadero (1871), de Esteban Echevarría o Amalia (1855), de José Mármol. Tiempo después Carlos Fuentes, auténtico referente de todas las tendencias de la novela mexicana en la segunda mitad del siglo XX, plasmó en su novela La región más transparente (1958) la realidad de un México enfrentado en una suerte de reedición del conflicto civilización/barbarie encarnado respectivamente en los personajes de Federico Robles e Ixca Cienfuegos. La posición intermedia, representada por el intelectual Manuel Zamacona, que abogaba por la superación de conflictos y la unidad, se veía derrotada de forma simbólica con la muerte absurda del personaje, lo cual abocaba el relato a un final pesimista que, en la línea de otras obras de Fuentes, dejaba la imagen de un país desgarrado por facciones irreconciliables y en manos de unos políticos que habían lastrado su progreso.

En Si tú quieres, moriré, la pugna entre ambos planteamientos ideológicos toma cuerpo en las figuras de dos de sus principales representantes y enemigos acérrimos en la realidad: Gómez Farías y Lucas Alamán. El proyecto del primero defiende la necesidad de construir un futuro basado en el magisterio y la guía de países como Francia e Inglaterra, con un sistema de organización descentralizado, un recorte del poder de la Iglesia y un decidido impulso a la educación. Frente a él, la visión favorable de España y su legado, el apego a las tradiciones morales y religiosas del país, y su apuesta por un gobierno central fuerte, perfilan el talante conservador de Lucas Alamán"

Laveaga plantea además otro factor de gran relevancia en esta época que fue especialmente determinante en México, me refiero al papel disgregador que desde el primer momento repre-

4 Para más información sobre este personaje histórico y sus planteamientos ideológicos, ver el libro de Moisés Gómez Navarro (1952) 
sentaron los EEUU, interesados en generar desorden para culminar sus ambiciones expansionistas.

La Historia se ha encargado de contarnos lo que realmente ocurrió: las luchas entre facciones, encabezadas principalmente por Gómez Farías y Lucas Alamán, desgastan al país en pugnas intestinas que generan una gran inestabilidad. Estas circunstancias, conjugadas con la llegada al poder del controvertido general Santa Anna, son aprovechadas por el gobierno de EEUU para hacerse con el control de Texas y, más tarde, arrebatarle a México California y Nuevo México. El país, sumido en el caos, se ve derrotado y humillado por el vecino del norte, que le despoja de buena parte de su territorio en los momentos en los que de forma titubeante estaba intentando encontrar las bases sobre las que asentar su futuro. Desde entonces, en palabras de Carlos Fuentes, "la nueva frontera sobre el Río Bravo se convirtió, para muchos mexicanos, en una herida abierta" $(1992,286)$. Para Laveaga, este episodio traumático determinará el rumbo posterior del país, y en un momento del relato se plantea la pregunta que formula de este modo el imaginario Alamán, “¿hubo aspectos en nuestra historia que pudieron haber sido diferentes ante un giro insignificante?" (2018,30). En Si tú quieres, moriré, el punto de inflexión que marca el inicio del cambio se produce con la muerte accidental del caudillo mexicano al caerse del caballo cuando iba a deponer a su vicepresidente Gómez Farías, que en su ausencia había puesto en marcha una ambiciosa agenda liberal. Este hecho traerá como consecuencia que Farías permanezca en el poder y Santa Anna, desaparecido de la Historia, no pierda la mitad del territorio mexicano. A este episodio, fruto del azar, le siguen las decisiones que tomará el nuevo presidente. Aconsejado por la visionaria María Inés, Farías decide pactar con su gran enemigo Alamán, a quien mantenía encarcelado, lo cual provoca un giro radical en la marcha del país que, desde entonces, parece abandonar las antiguas rencillas e intrigas y unirse en un proyecto común. La mentora y consejera de Farías se encuentra también detrás de otra decisión a la postre trascendental: la venta de 
Texas a EEUU, un suceso que además de evitar la confrontación que condujo a la derrota, tendrá el efecto colateral de desestabilizar a los EEUU, de los que acaban desgajándose los estados del sur debido a las tensiones esclavistas. Ese "efecto mariposa" creado por el azar y las decisiones da como resultado un México que "se proyecta, imbatible, como una de las naciones más prósperas en el escenario internacional" $(2018,37)$, y que tiene un gran peso político en un mundo en el que los vecinos del norte, divididos y empobrecidos, apenas tienen relevancia alguna. Este sueño de una vida alternativa lanza incluso algunos guiños al presente, como la breve alusión al proyecto que defienden las fuerzas más conservadoras de México de construir un muro en la frontera para evitar la emigración descontrolada que ingresa al país desde el norte "con la intención de realizar los trabajos que los mexicanos preferirían no hacer" $(2018,245)$, un giro en la historia que, a buen seguro, causará en el lector nacional una mezcla encontrada de sensaciones. Las alusiones a estas alternativas de la Historia son constantes en los diálogos y reflexiones de los personajes, e incluso se llega a plantear un recurso metaliterario ya presente en El hombre en el castillo, cuando en ese universo alternativo Alamán y Farías comentan una novela de Manuel Payno, titulada La guerra de Texas, en la que el joven novelista escribe una ucronía en la que narra lo que realmente sucedió en el universo del lector, la guerra contra EEUU y la pérdida de parte del territorio (2018,280-281).

Para el autor, el futuro de México y de América Latina en su conjunto quedó marcado en esos años posteriores a la independencia debido principalmente a las divisiones internas y a las ambiciones personales de líderes políticos que, si en primera instancia acabaron con el sueño bolivariano de la unidad continental, se reprodujeron más tarde en las luchas intestinas surgidas en el seno de las repúblicas recién nacidas. Como señaló en su día Octavio Paz en relación a México: "Mientras disputan las facciones, el país se desintegra" $(1993,268)$. Laveaga propone de forma implícita realizar una lectura en clave contemporánea 
para que en el futuro el país no se encuentre abocado a repetir los mismos errores, "pensar qué debemos estar haciendo hoy para no lamentarlo mañana” $(2018,279)$, como verbaliza el imaginario Alamán en conversación con Farías. La respuesta más obvia se resume en una receta quizás en el fondo un tanto simplista y difícilmente alcanzable -y no solo en la política mexicana-, que apela a la necesidad de aprender las lecciones de la Historia, superar divisiones, aunar esfuerzos y desterrar de la vida pública el personalismo y la corrupción, una solución no muy diferente en el fondo de la que planteaba Fuentes en la novela anterior. Forzando un tanto la lógica de la Historia, Laveaga organiza su utopía ucrónica a partir del pacto, difícilmente creíble, entre dos enemigos tan enfrentados en la realidad como lo fueron Farías y Alamán y, a partir de ese nuevo punto de divergencia, nos invita a imaginar el porvenir de un México asentado sobre las bases de un proyecto común en el que, de forma particular, ha desaparecido el influjo negativo que los Estados Unidos han tenido históricamente en el devenir de América Latina. El autor presenta una realidad inversa en la que unidad ha premiado a México, mientras que la división del vecino del norte ha sido la causante de su decadencia.

Más allá de estos asuntos de índole política y económica, la novela incide en otros conflictos habituales en el debate histórico-cultural de México que tienen que ver con la reconciliación con el pasado, la aceptación del mestizaje y el debate sobre los proyectos encontrados que también en el plano identitario han enfrentado al país. Aunque en la novela de Laveaga no hay apenas alusiones concretas a la problemática de las comunidades indígenas, esa nueva bandera en la que se aúnan los colores rojo y amarillo de España con la efigie de Quetzalcóatl viene a suponer el símbolo del enriquecedor mestizaje de la nación como emblema principal de su identidad.

En la novela de Laveaga un acontecimiento fortuito -la muerte accidental de Santa Anna- será por tanto el que en primera instancia determine un cambio de rumbo en la Historia, pero a 
este hecho le siguen la decisiones personales -el pacto de Gómez Farías con Alamán en primer término- que acaban siendo tanto o más relevantes que el hecho casual. Del mismo modo que la novela anterior de Fuentes, Si tú quieres, moriré supone una respuesta a las visiones deterministas de la Historia, e invita al lector a cuestionar el papel de lo contingente en el destino tanto individual como colectivo.

\section{Viajes temporales e historias paralelas}

En las últimas décadas el planteamiento narrativo de las historias alternativas se realiza con frecuencia desde perspectivas que tienen su base en hipótesis científicas. La teoría cuántica de los universos paralelos o "multiverso", que fundamenta la base teórica de estos argumentos, implica también en el fondo una reflexión similar a la que planteaban los relatos anteriores. Con cada decisión o pequeña variación fortuita o voluntaria sucedida en un determinado momento de la línea temporal se origina un nuevo universo de opciones, un nuevo camino en la Historia que transcurre en paralelo con otros hasta conformar una serie infinita de realidades posibles. Las "parallel worlds stories", como las denomina Karen Hellekson $(2001,4)$ difieren según esta autora de las "ucronías puras" (Pestarini 2017,421) como la de Lavegaga en que en ellas no existe un "nexus event" concreto, sino que este tipo de relatos "asume that history can change at almost any point, no matter how apparently insignificant" $(2001,9)$. Se podría añadir también que frente a la única línea temporal de la ucronía "pura", en este caso son varias las historias que transcurren de forma simultánea y con frecuencia los personajes tienen la opción de viajar entre estas dimensiones por medio de determinados "portales".

La creación de mundos paralelos se relaciona también de forma directa con el tópico narrativo del viaje en el tiempo, una línea argumental de la que existen pocos ejemplos en la literatura mexicana. En la novela que inaugura esta temática en el país, Palamás, Echevete y yo, o el lago asfaltado (1945) su autor, Diego 
Cañedo, analizaba la realidad de su época a través de la óptica del viajero que llega desde el futuro a ese México de los años 40 y desde ahí se dirige hacia otras épocas del pasado. En las distintas etapas de su periplo temporal, la época prehispánica, el siglo XVII y los años 40 del siglo XX, el personaje principal, Palamás, y su acompañante Echevete, son testigos de la pervivencia de una estructura social caracterizada por el dominio de una minoría poseedora de numerosos privilegios, en tanto que el pueblo llano sufre los violentos métodos represivos puestos en práctica por los poderosos y los gobernantes. La ciencia ficción surge ya entonces como una forma de ofrecer una nueva perspectiva sobre la historia de un país en el que bajo distintas máscaras se han reiterado durante siglos los mismos mecanismos de poder, una reflexión que recuerda muy de cerca a las teorías que poco tiempo después plasmará Octavio Paz en su ensayo anteriormente mencionado. No obstante, a diferencia de este último y en consonancia con el mensaje positivo que impregna toda su obra narrativa, Cañedo expresa en esta novela su esperanza en el futuro al describir ese mundo del que procede Palamás como un lugar en el que todos los problemas que aquejaban al presente del país pertenecían a un pasado ya superado $(1945,263)$.

El problema que presenta a nivel argumental esta novela de Cañedo reside en la falta de coherencia a la hora de plantear un desarrollo lógico de los acontecimientos que solvente el escollo argumental de las paradojas temporales y que en consecuencia vaya acorde con el requisito de verosimilitud propio del género. Los hechos que protagonizan Palamás y Echevete en el siglo XVII podrían haber supuesto una modificación en la cadena posterior de sucesos de la Historia, pero esto no sucede en ningún momento ni tampoco se reflexiona sobre ello. Este hecho es todavía más evidente en otra novela que también refiere un viaje al pasado, Adamas (1995), de Héctor Chavarría, donde las confusiones y las posibles paradojas temporales no resueltas llegan a ser de tal calibre que el propio autor en un "Post-scriptum" reconoce la total falta de lógica en los sucesos del relato (1995,134-135). 
En este sentido, y a pesar de la poca estima que Fernando Ángel Moreno parece tener a este recurso, que ha definido como "una excusa argumental no demasiado brillante" $(2010,272)$, lo cierto es que la creación de universos paralelos nacidos después de cada modificación en la línea temporal supone desde el punto de vista narrativo el mecanismo perfecto para solventar estos desajustes lógicos y dotar a estas historias de una mayor coherencia y verosimilitud interna, al tiempo que sirve para entroncar estos argumentos con la prédica científica que con frecuencia les sirve de base teórica.

En Tiempo lunar (2005), de Mauricio Molina, se especula sobre la existencia de "portales" que dan acceso a realidades alternativas que permiten vislumbrar también otros futuros posibles. La acción central se sitúa en un porvenir indeterminado en el que un acontecimiento que no se define provoca que se cierre el paso a varias zonas de la capital. En este espacio postapocalíptico, el protagonista, Andrés, sigue la pista de su amigo Ismael, desaparecido en circunstancias extrañas, y guiado por las anotaciones que este ha dejado en su cuaderno, accede a una zona de la ciudad en la que existen estas fisuras en la curva espacio-temporal, “archipiélagos en el océano de las leyes naturales" (2005,110), que han sido las causantes de misteriosas desapariciones de personas, como parece haber ocurrido en el caso de Ismael. Andrés vive en la Ciudad de México en un tiempo en el que el espacio urbano se ha convertido en un lugar prácticamente despoblado tomado por militares y policía, donde predominan "los edificios en ruinas, las zonas devastadas, los parques muertos" $(2005,31)$ y sobre el que cae una "incesante lluvia ácida" $(2005,80)$, al tiempo que en todo el planeta la disminución de la capa de ozono ha provocado que el sol se vea como una "enorme naranja infectada" $(2005,49)$. En este aspecto, Tiempo lunar participa de la sensibilidad ecologista común a la gran mayoría de los relatos distópicos mexicanos, que utilizan la mirada prospectiva para describir un futuro devastado por la acción del ser humano, una denuncia que se hace especialmente evidente en novelas como Cristóbal 
Nonato (1987), de Carlos Fuentes, La leyenda de los soles (1993) o ¿En quién piensas cuando haces el amor? (1996), de Homero Aridjis, Que Dios se apiade de todos nosotros (1993), de Ricardo Guzmán Wolffer, Memoria de los días (1995), de Pedro Ángel Palou, El salmo del milenio (1998), de Ramón López Castro, o México sediento (2008), de Francisco Martín Moreno. En la mayoría de estos relatos, la naturaleza termina cobrándose su venganza contra sus maltratadores mediante la destrucción de la ciudad por la acción de terremotos (La leyenda.. ¿En quien piensas..), incendios (Cristóbal Nonato) o erupciones volcánicas (El dedo de oro (1996), de Guillermo Sheridan). Esto mismo sucede en Tiempo lunar, donde Andrés, en su visión de un futuro posible, contempla la desaparición de la capital, construida en el espacio que los nativos llamaron "El lugar del Ombligo de la Luna" $(2005,68)$, anegada por las aguas que en otro tiempo cubrieron la zona

El agua verde se acumulaba en los hundimientos de las iglesias y los edificios coloniales, en los estacionamientos y sótanos de las construcciones recientes. Parte de la catedral estaba hundida, las calles a esa hora que ningún ojo las miraba se iban convirtiendo en canales, como antaño. El Zócalo era ya una enorme laguna (2005,9293).

Tiempo lunar representa un caso claro de hibridación entre el presupuesto cienciaficcional de base (la existencia de portales que dan acceso a tiempos diferentes y realidades alternativas) y mitos de distinta procedencia que sirven de intertextos para la creación de algunos personajes y argumentos. El ejemplo más significativo lo constituye la enigmática y atemporal Malena, cuya relación con el astro nocturno se establece a través del lunar que tiene en su muslo izquierdo y que en un momento del relato se identifica con el personaje legendario de Melusina, mitad mujer mitad serpiente o pez, y emparentada por tanto con el ámbito de las antiguas deidades acuáticas (2005,99-106). Ella es un personaje que pertenece a todos los mundos y a todos los tiempos, 
y en su función arquetípica encarna la relación entre mujer y naturaleza asociada a la idea de resistencia frente a los patrones de la modernidad, un tema frecuente en las expresiones artísticas de sesgo ecologista, cuyos creadores ligan el deterioro ambiental con la pérdida de la sensibilidad hacia el medio natural nacida como consecuencia del cambio de la sociedad hacia un modelo androcéntrico (Binns, 2004,31). La luna se asocia también, como señala Mircea Eliade (1972,83-85), con la idea del ciclo, del retorno y por lo tanto de la regeneración, un contenido acorde con la conclusión del relato en que en ese potencial porvenir se sugiere el regreso de un pasado que simbólicamente se toma su venganza sobre ese mundo casi destruido por la mano del hombre. Molina recurre en este caso a leyendas procedentes del mundo prehispánico, y en especial a la que profetiza un futuro renacer del mundo antiguo que acabará derrotando a los antiguos invasores. Itala Schmelz resume así el desenlace de esta profecía:

La capital del gran reino azteca, que fuera sometida y conquistada por los españoles, se sacudirá la imposición de occidente, superando la historia de dominio y postración. En un futuro emponzoñado por la modernidad que trajo occidente, renacerán los dioses de esta tierra y ahogarán a la capital en sus inmundicias $(2012,6)$.

Tiempo lunar es por tanto una novela de complejo simbolismo que en primera instancia remite a contenidos comunes en la narrativa contemporánea de México que aluden al fracaso de la modernidad y abogan por una necesaria regeneración. Debido a esa hibridación entre la mirada prospectiva y contenidos pertenecientes al pasado cultural de México, Gabriel Trujillo Muñoz la ha considerado como "la punta del iceberg de toda una nueva sensibilidad, de una ciencia ficción que regresa a los símbolos prehispánicos, a la magia ancestral tan cara a Lovecraft y a Machen. Es la unión incestuosa entre Huitzilopochtli y Cthulhu" (2016,190).

La creación de mundos alternativos a partir de la hipótesis del multiverso constituye la base principal en la construcción del 
argumento en Laberinto (1994) y Trenes perdidos en la niebla (2010), de Gabriel Trujillo Muñoz.

Ambas novelas presentan una estructura compleja caracterizada por el fragmentarismo y la dislocación temporal. En $\mathrm{La}$ berinto, los segmentos narrativos que refieren la aventura de la nave Iliria y los tripulantes de la misma que acceden al enigmático Laberinto situado en un punto del espacio, tienen lugar en un periodo indeterminado del mismo año: 2224, pero se refieren sin responder a un orden lineal. Estos fragmentos, de extensión variada, se alternan con notas de prensa, artículos científicos o extractos de memorias personales, que abarcan un amplio espectro temporal que llega incluso hasta el año 3820. Estos párrafos, escritos en cursiva, ofrecen información contextual sobre los antecedentes, motivos, desarrollo, conclusión y efectos posteriores de la misión del Iliria y, de nuevo, su aparición dista de guardar un orden cronológico. La novela exige por tanto de un lector paciente que sea capaz de no perderse en el verdadero laberinto narrativo que el texto plantea. Algo similar hallamos en Trenes.., donde un grupo de científicos del futuro pretende paliar los efectos del holocausto judío del siglo XX mediante el rescate de grupos que viajan en trenes rumbo al exterminio, y que por medio de un artilugio que permite trasladarse en el tiempo, son conducidos a otro momento y a otras tierras. Cada viaje temporal va abriendo nuevas líneas posibles, y en la que más se desarrolla en el texto los rescatadores establecen a los judíos en un territorio desértico de Baja California a finales del siglo XIX en cumplimiento de un viejo proyecto sionista que localizaba en este lugar la tierra prometida. La dedicación al trabajo de estos pioneros y sus descendientes, y la inexistencia de conflictos territoriales, dan como resultado que México en los siglos XX y XXI se convierta en una potencia económica mundial. En otra de las líneas posibles, uno de los viajeros evita el holocausto con el simple hecho de comprarle unos cuadros al joven Hitler, que con este impulso se vuelca en su carrera artística y con los años se convierte en un pintor famoso. La estructura es de nuevo fragmentaria y 
los distintos segmentos abarcan como en el caso anterior distintas perspectivas y un amplio espectro temporal de referencias en un periodo que oscila entre 1897 y 2218.

Trujillo lleva a cabo en ambas novelas una reflexión similar sobre la dolorosa historia del mundo en el siglo XX centrada particularmente en el nazismo y especula sobre la posibilidad de intervenir en el curso de la Historia para modificar su rumbo y crear de este modo las condiciones para el desarrollo de un futuro diferente. En Laberinto, la "utopía racista" de Hans Boder, que le lleva a crear en 2078 un experimento científico para generar una especie humana libre de taras psíquicas, recuerda muy de cerca las teorías eugenésicas del Tercer Reich, y de hecho en ese Laberinto al que el personaje y sus secuaces se ven obligados a escapar, donde confluyen todos los tiempos y espacios y se diluyen las identidades, Bolder y los suyos reaparecen transformados de forma significativa en el Führer y un ejército de nazis, y comienzan a perseguir a través de distintos escenarios tempo-espaciales a los miembros del Comando Guevara, responsables del fracaso del experimento y que también asumen el papel de algún icono representativo del imaginario occidental. Antes del definitivo colapso final, los tripulantes del Iliria consiguen viajar atrás en el tiempo con el fin de impedir el desarrollo del experimento de Bolder, aunque son conscientes no de haber corregido el pasado, sino de haber iniciado una línea temporal distinta, uno más de los infinitos universos posibles. Como señala la doctora Almeida, líder del Comando, Bolder "ha muerto muchas veces, en diversos tiempos y espacios (...). Pero en otros tiempos y espacios sigue con vida y conspirando contra la humanidad" (1994,139).

En última instancia, Laberinto y Trenes perdidos en la niebla plantean una nueva reflexión sobre la idea del Mal, que en el siglo XX encarnó de forma especial el régimen nazi y que en el siglo XXII simbolizan Bolder y sus secuaces. La semilla de odio, violencia e intolerancia que anida en el ser humano y de la que hasta época no muy reciente ha sido víctima la comu- 
nidad judía, se encuentra presta a germinar de nuevo en cualquier momento sobre cualquier otro colectivo racial o religioso y las etapas oscuras de nuestra historia que se creían superadas pueden volver a repetirse. De esta forma, los trenes que en un principio transportaban judíos, se cargan con el tiempo con otros refugiados, camboyanos, armenios, polacos, tibetanos y palestinos, que huyen de la persecución en sus respectivos países $(2010,259)$. Pero el autor también presenta la otra cara de la moneda encarnada en aquellos personajes "positivos" que siempre han luchado contra la intolerancia. En el fondo, los relatos de Trujillo remiten a la eterna lucha cósmica entre el Bien y el Mal, un concepto que constituye la base de la mayoría de los distintos sistemas mitológicos y religiosos de la Humanidad y que en el ámbito de la narrativa mexicana se erige en el principal núcleo teórico de la extensa novela de Carlos Fuentes Terra Nostra (1975). La hipótesis científica del multiverso ofrece en este caso la imagen de distintos mundos posibles en los que se han producido diferentes alternativas en esa pugna entre principios contrapuestos. La victoria de unos u otros no será nunca definitiva, pero lo realmente importante, parece señalar el autor, es hacerles frente a esas fuerzas que, con distintos disfraces y apariencias, han encarnado y encarnan el odio al diferente. Ambas novelas proponen una toma de conciencia sobre las terribles consecuencias que el rechazo del "otro" ha supuesto en épocas no tan lejanas y por extensión sobre los crímenes que se han cometido y se siguen cometiendo amparados en supuestas convicciones de índole nacionalista o religiosa. En este aspecto, el poso ideológico de los dos relatos no difiere en exceso de lo que a través de novelas de carácter histórico mostraron autores contemporáneos como Jorge Volpi o Ignacio Padilla, que en obras como En busca de Klingsor (1999) o Amphitryon (2000) reflejaron el mal del siglo XX encarnado de nuevo en el régimen nazi, en unos argumentos que exceden el contexto mexicano para convertirse en reflexiones sobre la historia reciente del mundo occidental. 


\section{Conclusión}

De lo señalado en páginas anteriores se puede percibir la existencia de distintos matices a la hora de presentar narrativamente el tópico de la historia alternativa en la narrativa mexicana reciente. En primera instancia, la ucronía pura se relaciona con las especulaciones filosóficas que consideran la voluntad y el azar como forjadores del porvenir. En una línea que arranca desde los análisis históricos de la llamada "filosofía de lo mexicano" que se reflejan en relatos como La muerte de Artemio Cruz de Carlos Fuentes, Gerardo Laveaga imagina en su novela qué habría pasado de haberse producido una modificación en la Historia y propone una reflexión sobre los momentos en los que México perdió la oportunidad de alterar su destino. Sin dejar de lado este tipo de contenidos de raigambre existencialista, otro tipo de ucronías suelen tener su fundamento teórico en hipótesis científicas y se desarrollan a partir del tópico del viaje temporal o interdimensional, como sucede en Tiempo lunar y las dos novelas estudiadas de Gabriel Trujillo Muñoz. En todos los casos, la propuesta de un futuro o un universo alternativo nos sitúa ante la realidad de un presente poco halagüeño al tiempo que nos permite vislumbrar la evolución de una Historia, en especial la contemporánea, que tanto en clave nacional (Laveaga y Molina), como en un aspecto más universal o genérico (Trujillo Muñoz), ha estado marcada por el clasismo, la intolerancia, la violencia y el rechazo al diferente. Los escritores mexicanos de las últimas décadas coinciden en este sentido en ofrecer a través de esta nueva mirada que proporciona la ciencia ficción una interpretación muy poco complaciente de la Historia, en particular de su propio país, y proponer medidas de regeneración que se encuentran formuladas de forma implícita en esos soñados mundos paralelos.

\section{Referencias bibliográficas}

Alcocer, R.J. (2011) Time Travel in the Latin American and Caribbean Imagination. Re-reading History, New York, Palgrave Macmillan, 
Beск, H. (2008) "Sobre la historia contrafactual”, Letras Libres, 118, 14-15.

Binss, N. (2004) ¿Callejón sin salida? La crisis ecológica en la poesía hispanoamericana, Zaragoza, Prensas Universitarias de Zaragoza.

Cano, L. C. (2006) Intermitente recurrencia. La ciencia ficción y el canon literario hispanoamericano, Buenos Aires, Corregidor.

Capanna, C. (1996) El sentido de la ciencia ficción, Buenos Aires, Columba.

CAÑedo, D. (1945) Palamás, Echevete y yo, o el lago asfaltado, México, Stylo.

Chavarría, H. (1995) Adamas, México, Posada.

Córdoba Cornejo, A. (2011) ¿Extranjero en tierra extraña? El género de la ciencia ficción en América Latina, Sevilla, Ediciones de la Universidad de Sevilla.

Dímz Сово, R.M. (2009) "La reescritura de la Historia en la narrativa mexicana contemporánea", en González Boixo, José Carlos (ed.): Tendencias de la narrativa mexicana actual, Madrid / Frankfurt, Iberoamericana / Vervuert, 31-80.

Eliade, M. (1972) El mito del eterno retorno, Madrid, Alianza Editorial.

Freedman, C. (2000) Critical Theory and Science Fiction, Middletown, Wesleyan University Press.

Fuentes, C. (1992) El espejo enterrado, México, FCE.

Fuentes, C. (1962) La muerte de Artemio Cruz, México, FCE.

Ginway, M. E. and A.Brown (eds.) (2012) Latin American Science Fiction. Theory and Practice, New York, Palgrave McMillan.

Gómez Navarro, M. (1952) El pensamiento político de Lucas Alamán, México, El Colegio de México.

Gunn, J. and M. Candelaria (eds.) (2005) Speculations on Speculation. Theories of Science Fiction, Lanhanm, Scarecrow Press.

Haywood Ferreira, R. (2011) The Emergence of Latin American Science Fiction, Middletown, Wesleyan University Press.

Hellekson, K. (2001) The Alternate History: Refiguring Historical Time, Kent, Ohio State UP. 
Jameson, F. (2009) Arqueologías del futuro. El deseo llamado utopía y otras aproximaciones de ciencia-ficción, Madrid, Akal.

Laveaga, G. (2018) Si tú quieres, moriré, México, Planeta.

López-Lozano, M. (2008) Utopian Dreams, Apocalyptic Nightmares. Globalization in Recent Mexican and Chicano Narrative, Indiana, Purdue University Press.

Menton, S. (1993) La nueva novela histórica de la América Latina, 1979-1992, México, FCE.

Molina-Gavilán, Y. (2002) Ciencia ficción en español. Una mitología moderna ante el cambio, Levinston, The Edwin Mellen Press.

Molina, M. (2005) Tiempo lunar, México, Punto de Lectura.

Moreno, F.A. (2010) Teoría de la literatura de ciencia ficción. Poética y retórica de lo prospectivo, Vitoria, Portal Editions.

PAz, O. (1993) El laberinto de la soledad, Madrid, Cátedra.

Pons, M. C. (1996) Memorias del olvido: La novela histórica de fines del siglo XX, Mexico, Siglo XXI.

Pestarini, L. (2017) “Las ucronías en la literatura argentina”, Revista Iberoamericana, 259-260, 419-428.

Price, B. (2018) “Historias que no fueron: La ucronía, el steampunk y la reinvención del Segundo Imperio Mexicano en "La bestia ha muerto" de Bernardo Fernández (Bef)," Alambique: Revista académica de ciencia ficción y fantasia / Jornal acadêmico de ficção científica e fantasía, Vol.5 Iss. 2. DOI: http://dx.doi.org/10.5038/21676577.5.2.2 https://scholarcommons.usf.edu/alambique/vol5/iss2/2

Reati, F. (2006) Postales del porvenir: la literatura de anticipación en la Argentina neoliberal (1985-1999), Buenos Aires, Edit. Biblos.

Rivas, L.M. (2004) La novela intrahistórica. Tres miradas femeninas en la historia venezolana, Caracas, Ediciones El otro, el mismo.

Schmelz, I. (2012) “El DF en tono apocalíptico. La literatura mexicana de ciencia ficción y la Ciudad de México", Artelogie, 2, 1-9. http://cral.in2p3.fr/artelogie/spip.php?article89

SEeD, D. (2011) Science Fiction. A Very Short Introduction, Oxford University Press.

Suvin, D. (1984) Metamorfosis de la ciencia ficción. Sobre la poética y la historia de un género literario, México, FCE. 
Trujillo Muñoz, G. (1994) Laberinto (as time goes by), Mexicali, Instituto de Cultura de Baja California.

Trujillo Muñoz, G. (1999) Los confines: crónica de la ciencia-ficción mexicana, México, Vid.

Trujillo Muñoz, G. (2000) Biografías del futuro. La ciencia ficción mexicana y sus autores, Méxicalli, Universidad Autónoma de Baja California.

Trujillo Muñoz, G. (2010) Trenes perdidos en la niebla, México, Jus.

Trujillo Muñoz, G. (2016) Utopías y quimeras. Guía de viaje por los territorios de la ciencia ficción, México, Jus. 
